\title{
Stage IVA Unknown Primary Tumor (Except for EBV-Related and HPV-Related Tumors) and Metastatic Cervical Adenopathy AJCC v8
}

National Cancer Institute

\section{Source}

National Cancer Institute. Stage IVA Unknown Primary Tumor (Except for EBV-Related and HPV-Related Tumors) and Metastatic Cervical Adenopathy A/CC V8. NCI Thesaurus. Code $C 132678$.

Stage IVA includes: T0, N2, M0. T0: No evidence of primary tumor. N2: Metastasis in a single ipsilateral or contralateral cervical lymph node $3 \mathrm{~cm}$ or smaller in greatest dimension and $\mathrm{ENE}(+)$; or metastasis in a single ipsilateral cervical lymph node larger than $3 \mathrm{~cm}$ but not larger than $6 \mathrm{~cm}$ in greatest dimension and ENE(-); or metastases in multiple ipsilateral cervical lymph nodes, none larger than $6 \mathrm{~cm}$ in greatest dimension and ENE(-); or metastases in bilateral or contralateral cervical lymph nodes, none larger than $6 \mathrm{~cm}$ in greatest dimension and ENE(-). M0: No distant metastasis. (AJCC 8th Ed.) 